\title{
Mexico's transgenic maize under fire
}

\section{Experimental planting scheme has insufficient controls to prevent gene flow to native crops, critcs say.}

Mexico doesn't have an adequate system to monitor or protect natural maize (corn) varieties from transgenes, say prominent scientists concerned about the experimental planting of genetically modified crops.

In the past month, Monsanto and Dow AgriSciences have received government permission to plant transgenic maize across 24 plots, covering a total of nearly 13 hectares, in the northern states of Sonora, Sinaloa, Chihuahua, Coahuila and Tamaulipas. The planting of transgenic maize had been prohibited for 11 years in Mexico, where maize was first domesticated.

The experiments are meant to test hardier varieties of the crop, and federal officials say that they are implementing controls to prevent gene flow.

Ariel Álvarez Morales, executive secretary of the Mexican Inter-Secretarial Commission on Biosafety of Genetically Modified Organisms, described the experimental planting as a compliance trial to see how the companies and the plants perform. "We want to see how the planting will work in these conditions," he says. Plots will be less than half a hectare in area, seed-planting will occur at different times from that of natural varieties, and farmers will be surveyed about the effect on native maize.

In Sonora, where Monsanto has begun planting, transgenic maize is kept 500 metres away from conventional maize fields, says Eduardo Perez Pico, the firm's chief of research and regulatory affairs for the Latin American region.

However, nearly 2,000 scientists have signed

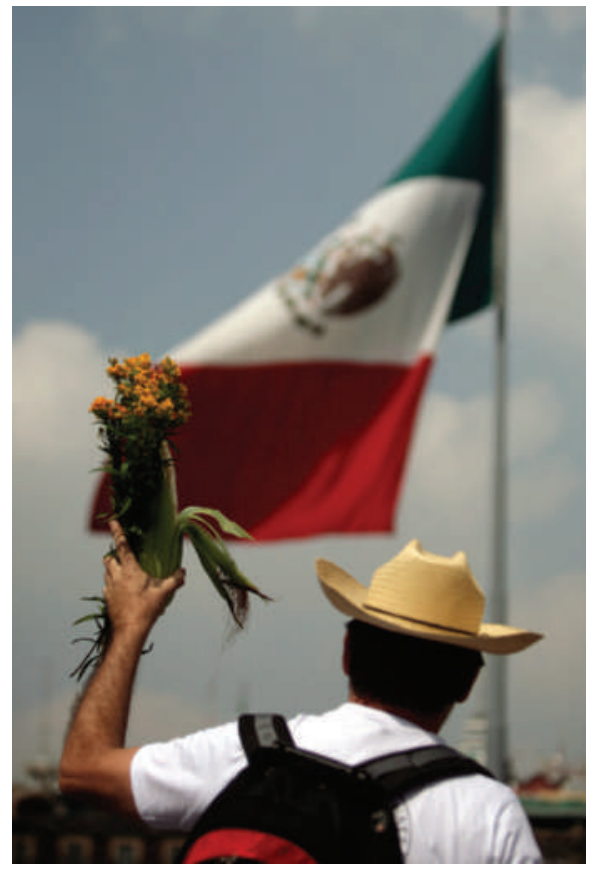

Activists question Mexico's transgenic maize.

a petition to block the experiments. "There is no way to stop gene flow to the native crops," says signatory Montgomery Slatkin, a geneticist at the University of California, Berkeley. Greenpeace and other groups filed a legal challenge, which the government has rejected.

"If Mexico experimentally plants transgenic maize, it should be done with ideal experiments

\section{Maize genome sequenced}

Geneticists have sequenced the genome of maize (corn), one of the world's most widely grown grains, a feat that should accelerate efforts to develop improved crop varieties to meet the world's growing hunger for food, animal feed and fuel.

The genome "is really a tremendous resource", says John Doebley, a maize geneticist at the University of Wisconsin-Madison. "It gives us a tool for mapping genes that we didn't have."

The four-year, US\$31million project to sequence maize (Zea mays) was led by a US-based consortium of researchers who decoded the genome of an inbred line of maize called B73, an important commercial crop variety.

The 2.3-billion-base sequence - the largest genetic blueprint yet worked out for any plant species - includes more than 32,000 proteincoding genes spread across maize's 10 chromosomes. Sections of DNA called transposable elements, which can move around the genome and cause mutations, are the most abundant parts of the sequence.

"What we have here is a crucial part of the instruction manual for how you breed a better corn plant," says project leader Richard Wilson, director of the Genome Center at Washington University in St Louis, Missouri.

The genome was published last week in Science (P. S. Schnable et al. Science 326, 1112-1115; 2009), together with 14 companion analyses in Science and other

journals. Elie Dolgin

For more, see go.nature.com/ UXHHw4 and a great capacity to monitor them - but we don't have either," adds José Sarukhán Kermez, a Mexican biologist who has served in top ministerial posts and is a former rector of the Autonomous National University of Mexico (UNAM) in Mexico City.

One facet of the debate surrounds the US firm being used by the Mexican government to train and equip staff at two reference labs for transgene testing in Mexico City. The firm, Genetic ID, is a spin-off by John Fagan of the Maharishi University of Management in Fairfield, Iowa, which favours organic crops and transcendental meditation.

Álvarez Morales says the firm was chosen because of its widely known analytical techniques. But geneticist Elena Alvarez-Buylla, of UNAM's Institute of Ecology in Mexico City, questions whether the company's methods are sensitive enough to detect transgenes after several generations of plant growth. Earlier this year, her group reported that Genetic ID failed to detect transgenes in blinded samples ${ }^{1}$. Genetic ID responded that Alvarez-Buylla's results were due to sample contamination ${ }^{2}$, which she challenged ${ }^{3}$.

Jay Reichman, an authority on transgenic testing with the US Environmental Protection Agency in Corvallis, Oregon, says that "overall the combined evidence suggests" that at least two transgenes "were present within the plant tissues" in question. In particular, Reichman noted that Alvarez-Buylla showed newly grown test plants believed to harbour transgenes were resistant to herbicide, indicating that they bore transgenes just like commercial seeds modified to be herbicide resistant.

Fagan disputes the criticism. Still, he too is against transgenic planting, citing the potential contamination of native maize: "It is very, very unacceptable."

\section{Rex Dalton}

Piñeyro-Nelson, A et al. Mol. Ecol. 18, 750-761 (2009).

2. Schoel, B. \& Fagan, J. Mol. Ecol. 18, 4143-4144 (2009)

3. Piñeyro-Nelson, A. et al. Mol. Ecol. 18, 4145-4150 (2009).

\section{Correction}

In the News Feature 'The Disappearing Nutrient' (Nature 461, 716-718; 2009), Amit Roy was misquoted as saying there was a possibility of "market manipulation" with phosphates. His full quote was: "The biggest challenge is that concentration of supply is only in a few hands and there is the possibility of manipulation of supply, demand and prices." Roy did not mean to imply that there is a possibility of market collusion. 